\title{
Article \\ Effect of Connection Resistance between Cyclones and Backpass on Furnace Solids Suspension Density Profile and Circulation Rates in CFB
}

\author{
Guanwen Luo ${ }^{1} \mathbb{D}$, Leming Cheng ${ }^{1, *}$, Liyao Li ${ }^{1}$, Junfeng Wang ${ }^{2}$, Xiaoguo Jiang ${ }^{2}$ and Weiguo Zhang ${ }^{1}$ \\ 1 State Key Laboratory of Clean Energy Utilization, Institute for Thermal Power Engineering, \\ Zhejiang University, Hangzhou 310027, China; gwluo@zju.edu.cn (G.L.); liyao_li@zju.edu.cn (L.L.); \\ zwg121@zju.edu.cn (W.Z.) \\ 2 Harbin Boiler Company Limited, Harbin 150046, China; wangjfeng@hbc.com.cn (J.W.); \\ jiangxg@hbc.com.cn (X.J.) \\ * Correspondence: lemingc@zju.edu.cn
}

\section{check for} updates

Citation: Luo, G.; Cheng, L.; Li, L.; Wang, J.; Jiang, X.; Zhang, W. Effect of Connection Resistance between Cyclones and Backpass on Furnace Solids Suspension Density Profile and Circulation Rates in CFB. Energies 2021, 14, 6162. https://doi.org/ $10.3390 /$ en14196162

Academic Editors: Artur Blaszczuk, Hairui Yang, Franz Winter and Rafał Kobyłeck

Received: 20 August 2021

Accepted: 21 September 2021

Published: 27 September 2021

Publisher's Note: MDPI stays neutral with regard to jurisdictional claims in published maps and institutional affiliations.

Copyright: (c) 2021 by the authors. Licensee MDPI, Basel, Switzerland. This article is an open access article distributed under the terms and conditions of the Creative Commons Attribution (CC BY) license (https:/ / creativecommons.org/licenses/by/ $4.0 /)$.

\begin{abstract}
The connection section between cyclones and backpass is an important configuration in multi-cyclone circulating fluidized bed boilers (CFB). In this work, the resistance coefficient of different connection modes, and connection resistance distribution from each cyclone outlet to backpass (connection branch) in one mode are defined and calculated, in order to investigate their effects on furnace solids suspension density distribution and circulation rates. Three connection modes with different overall resistance coefficients were tested experimentally and analyzed by a 1.5-dimensional model in a four-cyclone scaling CFB apparatus. Both experimental and theoretical results show that, with larger overall resistance of a connection, there are more solids suspended in the furnace bottom and fewer in the top section. The investigation of the C-type connection has revealed that when the branch resistance of the connection decreases from branch No. 1-4, the solids suspension density and circulation rate from corresponding solids recycle loops (No. 1-4) increase. Moreover, the non-uniformity of connection branch resistance distribution will lead to uneven lateral solids suspension density distribution and circulation rates allocation. This effect is enhanced by growing superficial velocity.
\end{abstract}

Keywords: CFB; connection between cyclones and backpass; resistance; theoretical model; solids suspension density; solids circulation rate

\section{Introduction}

Circulating fluidized bed boilers have been widely utilized in the industry due to their high combustion efficiency, low emission, and fuel adaptability. As the boiler's capacity increased, the furnace size becomes larger, and more cyclones with solid recycle systems are applied. However, the distributions of solids suspension density on the cross-section in the furnace and solids circulation rates under each cyclone become more non-uniform. This will lead to an uneven temperature profile in a CFB furnace and then cause operation problems.

Previous studies have been conducted towards gas-solid hydrodynamics uniformity in a CFB with multiple cyclones. Results show operating conditions [1-7] and geometric factors [6-11] have influences on furnace solids suspension density and circulation rates distribution among cyclones. However, it was reported that the connection between cyclones and backpass might also have an effect. As some close research, Zhou et al. [1] indicated the non-uniform distributions of cyclone pressure drop in a symmetric six-cyclone CFB cold test rig, that the pressure drops of three cyclones implemented at the one side are 30-50 Pa greater than the cyclones in the other side. They attributed this effect to unequal length of connection ducts from cyclones to backpass at each side, leading to different resistance of connection ducts from both sides. Similarly, Song et al. [12] also discovered the better solid flow uniformity of three circulation loops on one side than another three 
loops in a six-cyclone $600 \mathrm{MW}$ CFB boiler. And they further put forward that the different connection resistance at each side might result in this. In addition, Mo et al. [13] reported the higher ash temperature and lower circulation rate in the solid recycle loops, if they were located further to the backpass in a multi-cyclone CFB boiler. With pressure equilibrium analysis, they proposed the reason is those solid recycle loops have larger resistance from cyclone outlet to backpass compare to other loops.

As the studies indicated above, the connection between cyclones and backpass has a potential impact on solids suspension profile in furnace and circulation rates distribution in a CFB. The connection resistance and resistance distribution from each cyclone outlet to backpass (connection branch) are reported essential to this. However, detailed studies on connection resistance and resistance distribution among connection branches are lacking. And their effect on furnace solids suspension density and circulation rates distribution in a CFB also remain unknown.

For those reasons, this article focuses on the connection between cyclones and backpass, to investigate the effect of connection resistance on furnace solids suspension density and solids circulation rates in a CFB.

Firstly, a four-cyclone scaling CFB model with measuring techniques is introduced in this article. Then, the definition and calculation of branch resistance in a connection, and overall resistance of A, B, and C-type connection modes are presented. To step further, a 1.5-dimentional theoretical model based on mass and pressure equilibrium is established to analyze the relationship among connection resistance, solids suspension density distribution, and solids circulation rates. After experimental system description and theoretical analysis, the results of solids suspension density and solids circulation rates with different connection modes of overall resistance are presented. Besides, this work also focuses on a particular connection mode (C-type mode) to explore the impact of resistance distribution among connection branches, so that the relationship among connection branch resistance distribution, furnace solids suspension density, and circulation rates allocation among four solids recycle loops will be discovered. Eventually, the influence of superficial velocity on furnace suspension density profile and solids circulation rates under different connections is investigated, with $F n$ conditions of 85.2, 91.4, 96.3, and 102.5.

\section{Experimental Setup}

\subsection{Basic Information of the CFB Test Rig}

The experiment was conducted on a CFB cold test rig (shown in Figure 1a). It consists of a furnace, four cyclones, solids recycle systems and a connection to the backpass. The bed solids were fluidized by primary and secondary air in the furnace and then entered the cyclones. The air exited from the cyclone outlets passes through the connection section to the backpass, then finally escapes to the atmosphere. Those solids collected by the cyclones return to the furnace via the solids recycle system. 


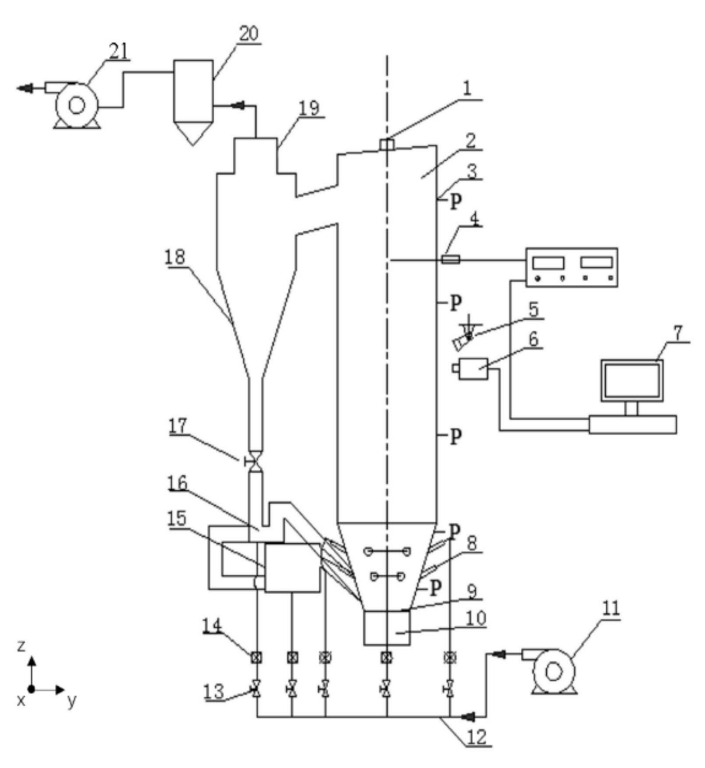

(a)

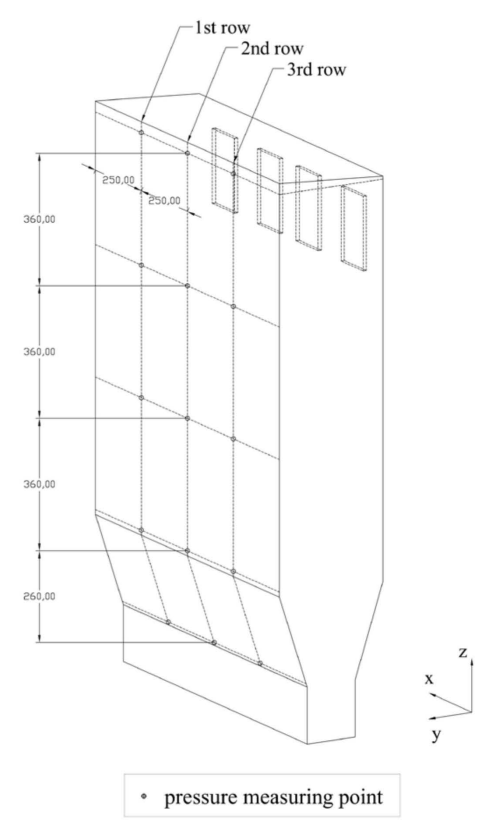

(b)

Figure 1. Schematic diagram and pressure measuring points of test rig: (a) schematic diagram of experiment. 1-bed material feeder, 2-furnace, 3-pressure taps, 4-pressure transmitter, 5-light, 6-high speed camera, 7-PC, 8-secondary air inlet, 9-distributor, 10-wind chamber, 11-input gas, 12-input gas duct, 13-ball valve, 14-rotameter, 15-External Heat Exchanger, 16-loop-seal, 17-cut off valve, 18cyclone, 19-connection to the backpass, 20-dust collector, 21-induced draft fan; (b) furnace pressure measuring points.

The geometric, operating, and bed material parameters are determined by a simplified fluid dynamic scaling rule [14] based on a $660 \mathrm{MW}$ supercritical CFB boiler. In the simplified Glicksman scaling law, a set of dimensionless groups are derived from governing equations of motion and mass. The dimensionless parameters are identified as:

$$
\frac{u_{g}^{2}}{\mathrm{~g} L}, \frac{u_{g}}{u_{m f}}, \frac{G_{s f}}{\rho_{s} u_{g}}, \frac{D}{L}, \Phi, P S D
$$

whereas $u_{g}$ and $u_{m f}$ are superficial velocity and minimum fluidized velocity respectively; $L$ and $D$ are the length and width of the furnace; $G_{s f}$ is solids flux at furnace and $\rho_{s}$ is solid density; The $\Phi$ is the sphericity of the particle; PSD is particle size distribution.

It needs to be noticed that only when particle Reynolds number $R e_{p}$ in the model is equal to or less than 4 , the simplified scaling law can be used [15].

Based on Glicksman scaling law, the geometric structure of the testing model is scaled down by 1:40 from the original CFB boiler. Besides, the operating parameters of the cold apparatus are designed and calculated. Table 1 gives the basic geometric parameters, operating conditions, bed material properties, and dimensionless numbers of both the original boiler and cold model. As shown in the table, all the dimensionless numbers between the cold model and the original boiler are nearly equaled. In addition, the particle Reynolds number in the cold model is close to 4 , which corresponds to the viscous limit condition for the simplified Glicksman scaling law. 
Table 1. Scaling parameters of original boiler and cold model.

\begin{tabular}{|c|c|c|c|c|c|}
\hline & Items & Symbols & Units & Values in Original Boiler & Values in Test Model \\
\hline \multirow{6}{*}{ Geometric parameters } & Height of furnace & $H$ & $\mathrm{~m}$ & 55.8 & 1.39 \\
\hline & Length of furnace & $L$ & $\mathrm{~m}$ & 39.95 & 0.99 \\
\hline & Width of furnace & $D$ & $\mathrm{~m}$ & 12.67 & 0.32 \\
\hline & Diameter of cyclone & $d_{c}$ & $\mathrm{~m}$ & 11.20 & 0.28 \\
\hline & Diamter of standpipe & $d_{s}$ & $\mathrm{~m}$ & 2.12 & 0.053 \\
\hline & $\begin{array}{l}\text { cross-section of the } \\
\text { non-mechanical valve }\end{array}$ & $A_{\text {dis }}$ & $\mathrm{m}^{2}$ & 4.84 & 0.0030 \\
\hline \multirow[t]{8}{*}{ Operating conditions } & Temperature & $T$ & ${ }^{\circ} \mathrm{C}$ & 880 & 25 \\
\hline & superficial velocity & $u_{g}$ & $\mathrm{~m} / \mathrm{s}$ & $4.37-5.26$ & $0.69-0.83$ \\
\hline & Air velocity in supply chamber & $u_{v s}^{\circ}$ & $\mathrm{m} / \mathrm{s}$ & - & 0.063 \\
\hline & Air velocity in recycle chamber & $u_{v r}$ & $\mathrm{~m} / \mathrm{s}$ & - & $0.19-0.38$ \\
\hline & Kinematic viscosity & $v$ & $\mathrm{~Pa} \cdot \mathrm{s}$ & $1.51 \times 10^{-4}$ & $1.55 \times 10^{-5}$ \\
\hline & Air density & $\rho_{f}$ & $\mathrm{~kg} / \mathrm{m}^{3}$ & 0.301 & 1.185 \\
\hline & Solids flux at furnace & $G_{s f}$ & $\mathrm{~kg} / \mathrm{m}^{2} \mathrm{~s}$ & 16.56 & 3.14 \\
\hline & Solids flux at a standpipe & $G_{s p}$ & $\mathrm{~kg} / \mathrm{m}^{2} \mathrm{~s}$ & 678.96 & 128.74 \\
\hline \multirow[t]{6}{*}{ Bed material properties } & Solid diameter & $d_{p}$ & um & 400 & 94 \\
\hline & Sphericity & $\Phi$ & & 0.8 & 0.8 \\
\hline & Minimum fluidized velocity & $u_{m f}$ & $\mathrm{~m} / \mathrm{s}$ & 0.052 & 0.0081 \\
\hline & Terminal velocity & $u_{t}$ & $\mathrm{~m} / \mathrm{s}$ & 2.91 & 0.66 \\
\hline & Particle Reynolds number & $R e_{p}$ & $\backslash$ & 11.13 & 4.02 \\
\hline & Solid density & $\rho_{S}$ & $\mathrm{~kg} / \mathrm{m}^{3}$ & 2000 & 2330 \\
\hline \multirow[t]{4}{*}{$\begin{array}{l}\text { Dimensionless } \\
\text { numbers }\end{array}$} & $u_{g}^{2} / g L$ & & $\backslash$ & 0.069 & 0.070 \\
\hline & $D / L$ & & $\backslash$ & 0.317 & 0.320 \\
\hline & $u_{g} / u_{m f}$ & & 1 & 102.08 & 102.11 \\
\hline & $G_{s f}^{0} / \rho_{s} u_{g}$ & & $\backslash$ & $1.57 \times 10^{-3}$ & $1.57 \times 10^{-3}$ \\
\hline
\end{tabular}

\subsection{Measurement Techniques}

The solids suspension density in the furnace was determined by the pressure drop. As shown in Figure 1b, there are three vertical rows of pressure measuring points along the bed length and 5 points in each row along with the bed height. The pressure taps were used to measure the furnace pressure profile. And solids suspension density $\rho_{s u s}$ is calculated as

$$
\rho_{s u s}=\frac{\Delta P}{\mathrm{~g} \Delta H}
$$

where $\Delta P$ is the pressure drop between two axial measuring positions with a distance of $\Delta H$. And g is gravitational acceleration with $9.81 \mathrm{~m} / \mathrm{s}^{2}$.

The solids circulation rate was measured at standpipe. Two methods were used to determine the solids circulation rate. The first one is measuring the height of the accumulating solid by cutting off the solids returning flow in the return leg within a specific time. The calculating solids circulation rate at standpipe " $i$ " $(i=1-4)$ is expressed as,

$$
G_{s p, i}=\frac{\rho_{s}\left(1-\varepsilon_{m f}\right) h_{s}}{t_{s}}
$$

where $h_{s}$ are the solids accumulating height within the specific time $t_{s}$.

Another methodology is particle tracking using a high-speed camera to trace the moving particles in the standpipe. The camera for tracking particles is HG-100K highspeed digital camera (REDLAKE company, New Hampshire, USA), with a resolution of $1154 \times 1128$ and a frame rate (fps) of 125 . The colored particles with similar density and diameter to bed material were used as tracer particles. For this method, the solids circulation rate at the standpipe " $i$ " can be calculated as 


$$
G_{s p, i}=\rho_{s} \frac{s}{t}
$$

where $s$ is the falling distance of tracer particle within specific time $t$. Figure 2 shows several successive frames of the capturing procedure. To ensure the accuracy of measuring, two or more colored particles with a similar relative location in each frame were treated as valid particles. And up to 1000 frames were used in total to measure and calculate $G_{s p, i}$ at each operating condition.

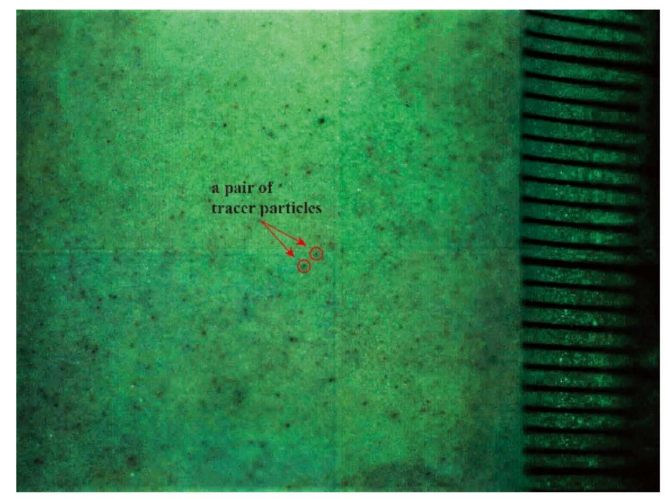

(a)

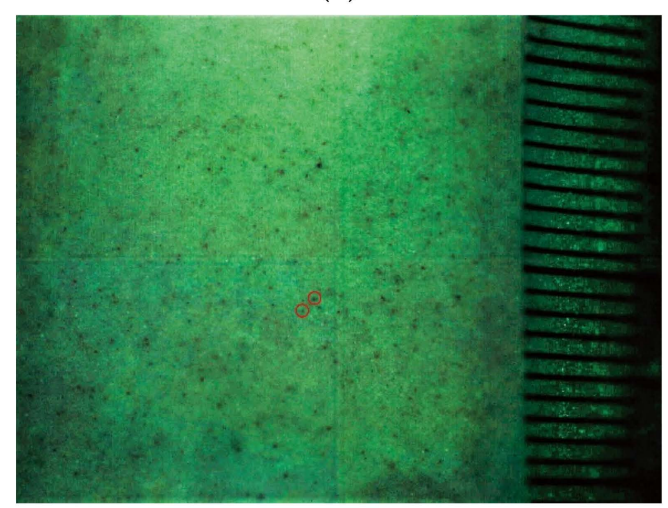

(c)

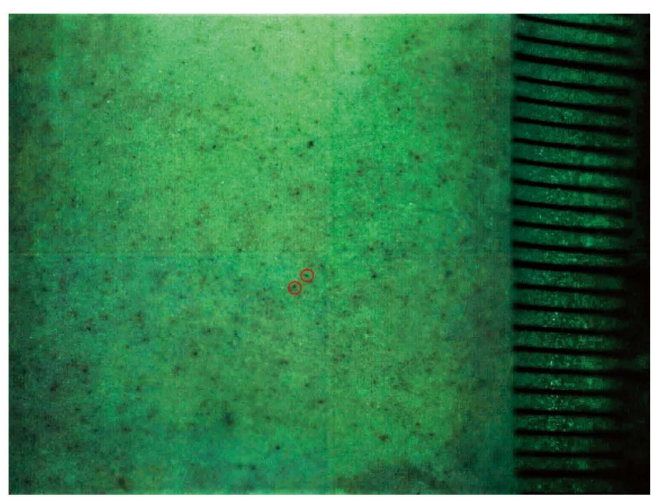

(b)

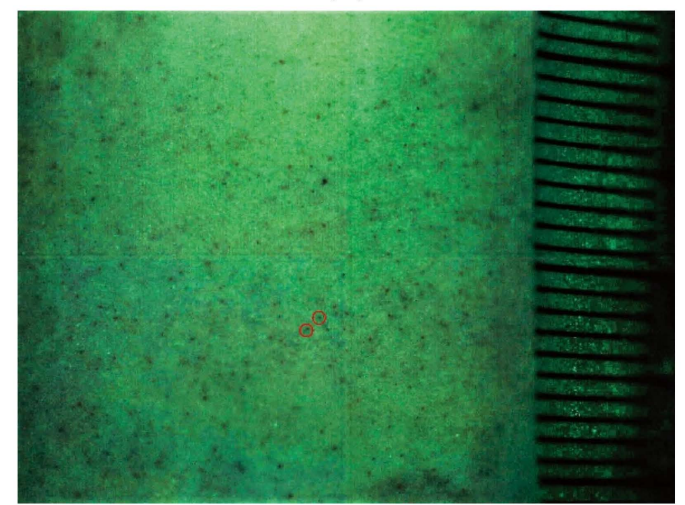

(d)

Figure 2. The successive frames of tracer particles are captured by a high-speed camera: (a) 1st frame; (b) 2nd frame; (c) 3rd frame; (d) 4th frame.

\section{Three Connection Modes and Calculation of Connection Resistance}

Three connection modes were tested in the cold apparatus as given in Figure 3. The overall resistance coefficients of each connection mode $\left(\xi_{a v}\right)$ were calculated based on the Handbook of Hydraulic Resistance [16]. They were determined by averaging the resistance coefficient of the four connection branches $\left(\xi_{b, i}\right)$. 


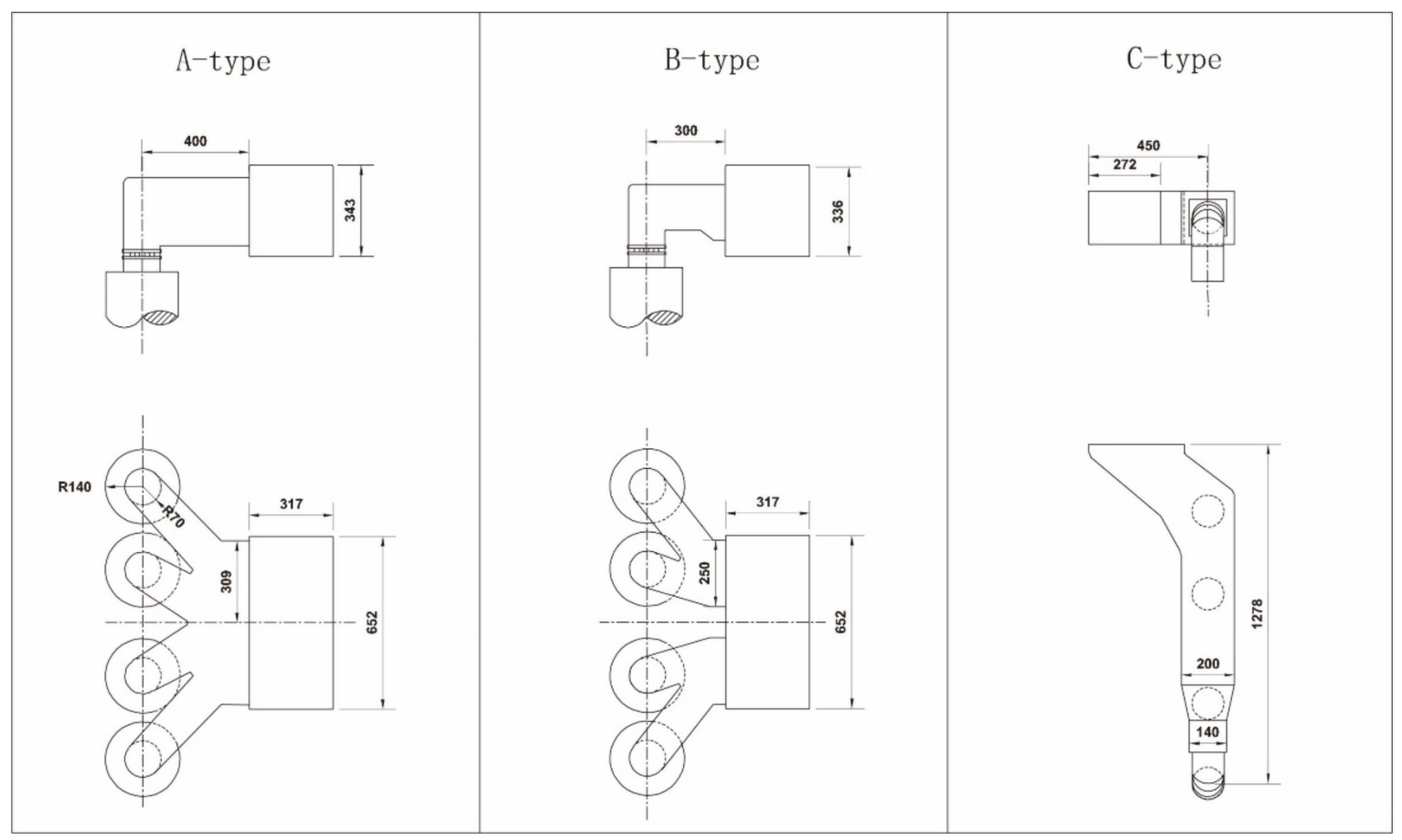

Figure 3. Three testing connection modes.

\subsection{Resistance Coefficient of Each Connection Branch of a Connection Mode}

The CFB system has four parallel cyclones, and the gas escaped from each cyclone outlet enters the connection section. Therefore, the connection section consists of four branches, starting from each cyclone outlet to the end of the connection, as illustrated in Figure 4. The resistance coefficient of a connection branch $\left(\xi_{b, i}, i=1-4\right)$ is calculated by summing the friction resistance coefficient along the path $\left(\xi_{f r, i}\right)$ and local resistance coefficients $\left(\xi_{l, i}\right)$ such as a sudden variation of cross-section area. The expression is given by,

$$
\xi_{b, i}=\xi_{f r, i}+\xi_{l, i}(\mathrm{i}=1-4)
$$

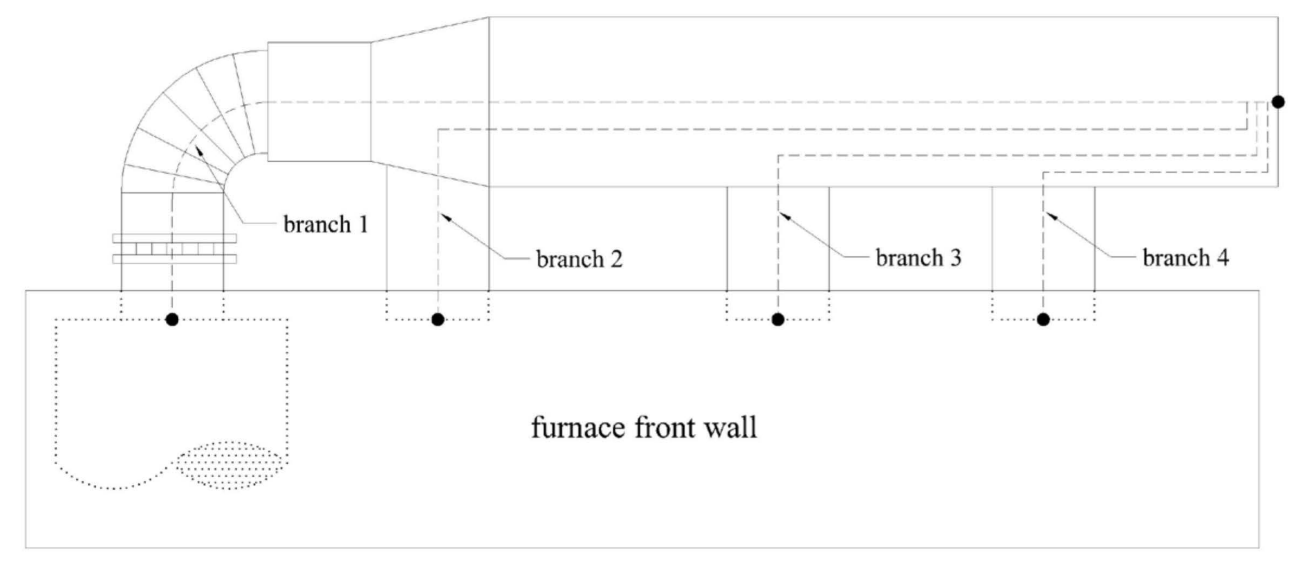

connection branches

- $\quad$ starts \& ends of connection branches

Figure 4. Structure of C-type connection mode (from the view of furnace front wall). 
For a connection branch $i$, the friction resistance coefficient can be expressed as,

$$
\xi_{f r, i}=\lambda \sum \frac{l}{D_{h}}
$$

where $\lambda$ refers to friction coefficient constant, $l$ and $D_{h}$ are the lengths and hydraulic diameter of the branch path, while the sections along the path might have different $D_{h}$.

$\xi_{l, i}$ is the local resistance coefficient, which is mainly decided by geometric parameters. According to Figure 4, taking branch 1 of the C-type connection as an example, the local resistance from the beginning to the end of this branch consists of an elbow, sudden expansion, tees junction, smooth variation, and horizontal band.

The frictional and local resistance coefficients of, A, B, and C-type modes are listed in Table 2. It is noted that the branches 1-4 of, A, B, and C-type are numbered based on cyclones' positions from left to right from the view the of furnace front wall, as hinted in Figure 4. Therefore, concerning symmetric structure of A and B-type connection modes, the connection resistance coefficient of branches 1 and 4, 2 and 3 of both A and B-type connections are equaled, respectively.

Table 2. Resistance coefficient calculation.

\begin{tabular}{|c|c|c|c|c|c|c|}
\hline Connection Mode & Connection Branch (i) & $\xi_{f r, i}$ & $\xi_{l, i}$ & Detailed of Local Resistance & $\xi_{b, i}$ & $\xi_{a v}$ \\
\hline \multirow[t]{2}{*}{ A-type } & 1 and 4 & 0.13 & 1.51 & $\begin{array}{l}\text { Elbow with right angle, conjunction wye with angle, sudden } \\
\text { expansion*2 }\end{array}$ & 1.64 & \multirow[t]{2}{*}{1.58} \\
\hline & 2 and 3 & 0.09 & 1.43 & $\begin{array}{l}\text { Elbow with right angle, conjunction wye with angle, sudden } \\
\text { expansion }{ }^{*} 2\end{array}$ & 1.52 & \\
\hline \multirow[t]{2}{*}{ B-type } & 1 and 4 & 0.12 & 1.60 & $\begin{array}{l}\text { Elbow with right angle, conjunction wye with angle, sudden } \\
\text { expansion*2, smooth expansion }\end{array}$ & 1.82 & \multirow[t]{2}{*}{1.70} \\
\hline & 2 and 3 & 0.09 & 1.49 & $\begin{array}{l}\text { Elbow with right angle, conjunction wye with angle, sudden } \\
\text { expansion }{ }^{*}, \text { smooth expansion }\end{array}$ & 1.58 & \\
\hline \multirow{4}{*}{ C-type } & 1 & 0.16 & 3.10 & $\begin{array}{l}\text { elbow, sudden expansion, tee (after junction) *3, smooth } \\
\text { expansion, horizontal elbow with sharp corner }\end{array}$ & 3.26 & \multirow{4}{*}{2.89} \\
\hline & 2 & 0.12 & 2.98 & $\begin{array}{l}\text { Tee before junction, tee after junction*2, smooth } \\
\text { expansion, horizontal elbow with sharp corner }\end{array}$ & 3.10 & \\
\hline & 3 & 0.08 & 2.66 & $\begin{array}{l}\text { Tee before junction, tee after junction, smooth expansion, } \\
\text { horizontal elbow with sharp corner }\end{array}$ & 2.74 & \\
\hline & 4 & 0.06 & 1.96 & tees before junction and horizontal elbow with sharp corner & 2.02 & \\
\hline
\end{tabular}

\subsection{Overall Resistance Coefficient of a Connection Mode}

For each type of connection mode, the connection section is divided into four parallel branches. Therefore, the overall resistance coefficient of a connection mode can be determined by averaging four branch resistance coefficients,

$$
\xi_{a v}=\frac{1}{4} \sum_{i=1}^{4} \xi_{b, i}
$$

As given in Table 2, the overall resistance coefficient of $\mathrm{A}, \mathrm{B}$, and $\mathrm{C}$ type connection modes are 1.58, 1.70, and 2.89 respectively. Other details about connection branch resistances are also given in Table 2.

\section{Theoretical Analysis}

In order to analyze the effect of the connection resistance on solids suspension density in furnace and solids circulation rates distribution theoretically, a 1.5-dimension model based on mass and pressure balance of the CFB system is deduced. 


\subsection{Solids Recycle Loops and Gas-Flowing Branches}

Solids recycle loop and gas-flowing branch in multi-cyclone CFB are defined in Figure 5. The furnace's cross-section is divided into four sections along the bed width, corresponding to four solids recycle systems. A divided furnace section, cyclone, and solids recycle system constitute one of the solids recycle loops (A-B-C-D-A). Similarly, the divided furnace section, cyclone, and connection branch (A-B-E-F) compose a gas-flowing branch, as shown in Figure 5. In the theoretical model, it is assumed gas-solid lateral interactions in the furnace upper section can be ignored, and solids lateral dispersion in the bottom dense section is counted [17].

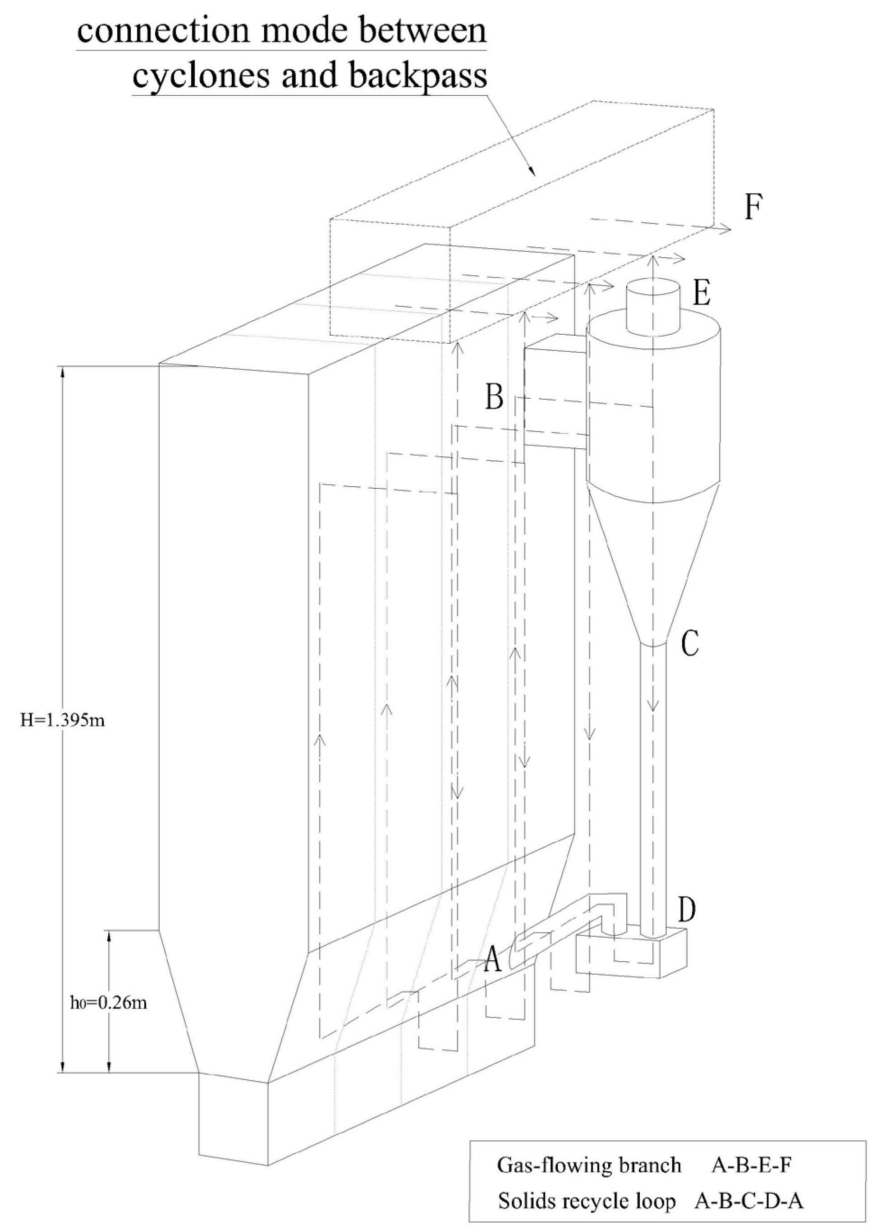

Figure 5. Diagram of gas-flowing branch and solids recycle loop.

For the reason of much narrower cross-section in a divided furnace, some researches regarding CFB riser are considered reasonable here. And each gas-flowing branch or solids recycle loop is denoted by subscript " $i$ " in the following theoretical analysis.

\subsection{Pressure Drops from Furnace to Each Connection Branch}

For branch A-B-E-F, the pressure drop relationship is expressed by the following equation,

$$
\Delta P_{A F, i}=\Delta P_{A B, i}+\Delta P_{B E, i}+\Delta P_{E F, i}
$$

where $\Delta P_{A B, i}, \Delta P_{B E, i}$ and $\Delta P_{E F, i}$ are the pressure drops across the furnace, cyclone, and the connection branch respectively. Since the primary air is evenly distributed above the distributor, $\Delta P_{A F, i}$ is identical for all four gas-flowing branches. 
$\Delta P_{A B, i}$ can be obtained as following [18],

$$
\Delta P_{A B, i}=\rho_{a v, i} g\left(H-h_{0}\right)+\rho_{a, i} g h_{0}
$$

where $\rho_{a, i}$ refers to solids suspension density in the bottom dense region with a height of $h_{0} . \rho_{a v, i}$ refers to axial average solids suspension density above $h_{0}$. The dense region height $h_{0}$ was taken approximately as $0.26 \mathrm{~m}$.

The pressure drop across the cyclone is estimated by Equation (10) [19]:

$$
\Delta P_{B E, i}=\frac{1}{2}\left(\frac{16 A_{c}}{D_{e}^{2}}\right) \rho_{g} u_{g c, i}^{2}
$$

where $A_{c}, D_{e}$ and $u_{g c, i}$ represent the cross-section area, hydraulic diameter, and gas velocity at the cyclone entrance, respectively.

Pressure drop across a connection branch $\Delta P_{E F, i}$ can be calculated by,

$$
\Delta P_{E F, i}=\frac{1}{2} \xi_{b, i} \rho_{g} u_{g o, i}^{2}
$$

where $u_{g o, i}$ is the equivalent gas velocity in a specific connection branch, $\xi_{b, i}$ represents the resistance coefficient of a connection branch calculated by Equation (5) in the previous section.

\subsection{Pressure Drops in a Solids Recycle Loop}

The sum of pressure drops of solids recycles loop is zero when the system operates steadily. It can be written as,

$$
\Delta P_{A B, i}+\Delta P_{B C, i}+\Delta P_{C D, i}+\Delta P_{D A, i}=0
$$

where $\Delta P_{A B, i}, \Delta P_{B C, i}, \Delta P_{C D, i}$ and $\Delta P_{D A, i}$ are the pressure drops across furnace, cyclone, standpipe, and loop-seal, respectively.

Here $\Delta P_{A B, i}$ and $\Delta P_{B C, i}$ are calculated according to Equations (9) and (10), respectively [20,21]. The pressure drop $\Delta P_{C D, i}$ in the standpipe of is calculated neglecting solids frictional or acceleration losses in standpipe [21]. It can be given,

$$
\Delta P_{C D, i}=\rho_{s}\left(1-\varepsilon_{m f}\right) g L_{i}
$$

here $L_{i}$ is solids stacking height in a standpipe.

The pressure drop across the non-mechanical valve can be written as [22],

$$
\Delta P_{D A, i}=\frac{1}{2 \rho_{s}\left(1-\varepsilon_{m f}\right)}\left(\frac{G_{s p, i} A_{s p}}{C_{d} A_{d i s} \varnothing}\right)^{2}
$$

where $A_{\text {dis }}$ is the vertical cross-section of the non-mechanical valve, $\varnothing$ is sphericity of the particle and $C_{d}$ is a discharge coefficient about $0.7-0.8$ for all kinds of systems and a mid-value of 0.75 was adopted.

\subsection{Mass Balance of the Loop in the Whole System}

Neglected the solids escaping from the cyclones, the solids mass is balanced in the CFB systems as following, 


$$
M=M_{s p}+M_{f}+M_{c y c}
$$

where $M$ is the total inventory in the system, which is $25 \mathrm{~kg}$ in this study. $M_{s p}, M_{f}$ and $M_{c y c}$ are the mass of solids in standpipes, furnace, and cyclones respectively. They can be written as following equations,

$$
\begin{gathered}
M_{s p}=\rho_{s}\left(1-\varepsilon_{m f}\right) A_{s p} \sum_{i=1}^{4} L_{i} \\
M_{f}=\left(\sum_{i=1}^{4} \rho_{a, i}\right) A_{f b} h_{0}+\left(\sum_{i=1}^{4} \rho_{a v, i}\right) A_{f d}\left(H-h_{0}\right) \\
=\bar{\rho}_{a} A_{f b} h_{0}+\left(\sum_{i=1}^{4} \rho_{a v, i}\right) A_{f d}\left(H-h_{0}\right) \\
M_{c y c}=k \sum_{i=1}^{4} \rho_{e, i}
\end{gathered}
$$

where $A_{f b}, A_{f d}$ and $A_{s p}$ are the cross-section area of furnace bottom, furnace above dense phase and standpipe, respectively; $M_{c y c}$ is calculated on the assumption that the solids concentration in the cyclone is the linear function to that of the dilute phase at the furnace exit [13]; $\rho_{e, i}$ is the solids suspension density at each furnace exit; $\bar{\rho}_{a}$ is the average solids suspension density at furnace bottom zone.

\subsection{Solids Suspension Density Distribution in the Furnace}

For each solids recycle loop, the axial solids suspension density above the dense region can be calculated by Kunii-Levenspiel Equation [23],

$$
\frac{\rho_{d, i}-\rho_{i}}{\rho_{d, i}-\rho_{a, i}}=\operatorname{Exp}\left[-a_{\varepsilon, i}\left(h-h_{0}\right)\right]
$$

where $a_{\varepsilon, i}$ is an axial attenuate coefficient, with the relationship of $a_{\varepsilon, i} \cdot u_{g, i}=C$, here $C$ increase from 4-12 with particle diameter from 88-369 $\mu \mathrm{m}$. Considering $94 \mu \mathrm{m}$ of particle diameter in this work, the $C$ value of 4 is adopted.

Besides, $\rho_{d, i}$ stands for saturated solids carrying capacity of gas, equivalent to solids suspension density at choking $[24,25]$. In this work, $\rho_{d, i}$ is calculated based on Yang's Equation [25],

$$
\frac{2 g D_{i}\left(\varepsilon_{d, i}^{-4.7}-1\right)}{\left(u_{g, i}-u_{t}\right)^{2}}=6.81 \times 10^{5} \frac{\rho_{g}}{\rho_{s}}
$$

where $D_{i}$ is the hydraulic diameter of the furnace section of a branch. $\varepsilon_{d, i}$ is choking voidage, also equivalent to the volume fraction of gas when saturated carrying occurs.

Then $\rho_{d, i}$ can be calculated as Equation (21) [23],

$$
\rho_{d, i}=\rho_{g} \varepsilon_{d, i}+\rho_{s}\left(1-\varepsilon_{d, i}\right)
$$

For the reason that the solids concentration in the bottom zone always has a lower value in the center of the furnace and increases towards the wall, $\rho_{a, i}$ can be determined by the modified Patience-Chaouki Equation [26],

$$
\frac{\bar{\varepsilon}_{a}^{0.6}-\varepsilon_{a, i}}{\bar{\varepsilon}_{a}^{0.6}-\bar{\varepsilon}_{a}}=3\left(\frac{r}{R}\right)^{4}
$$

where $r$ is the horizontal distance to the centerline of the furnace bed width and $R$ equals half bed width in a rectangular cross-section furnace. $\bar{\varepsilon}_{a}$ is the average voidage at the furnace bottom. $\bar{\rho}_{g}$ as well as $\rho_{a, i}$ can be calculated similarly to Equation (21) accordingly. 
Eventually, solids suspension density at furnace exit $\rho_{e, i}$ can be calculated by equation,

$$
\rho_{e, i}=\rho_{d, i}-\left(\rho_{d, i}-\rho_{a, i}\right) \operatorname{Exp}\left[-a_{\varepsilon, i}\left(H-h_{0}\right)\right]
$$

\subsection{Solids Circulation Rates}

The solids circulation rate at the standpipe in each recycle loop can be calculated by the following equation [27],

$$
G_{s p, i}=\rho_{e, i}\left(u_{g, i}-u_{t}\right) \frac{A_{f}}{A_{s p}}
$$

where $u_{t}$ is solid terminal velocity. The calculation of $u_{t}$ is provided in Appendix A.

Furthermore, the average solids circulation rate among four loops at standpipe $G_{s p}$ can be calculated,

$$
G_{s p}=\frac{1}{4} \sum_{i=1}^{4} G_{s p, i}
$$

\subsection{Solution Procedure}

With the equations listed above, the furnace solids suspension density distribution and solids circulation rate at standpipe can be determined for each solids recycle loop. They are related to the resistance coefficient of each branch in the connection between cyclones and backpass. Figure 6 gives the solution procedure of the theoretical model.

Step 1. System of equations solving

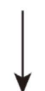

\begin{tabular}{|l|l|}
\hline $\begin{array}{l}\text { Basic unknowns } \\
(9 \text { vals })\end{array}$ & $L_{i}, u_{g, i}, \bar{\rho}_{a}$ \\
\hline
\end{tabular}

\begin{tabular}{|l|l|}
\hline $\begin{array}{l}\text { Basic eqs } \\
(9 \text { eqs })\end{array}$ & $(8),(12),(15)$ \\
\hline
\end{tabular}

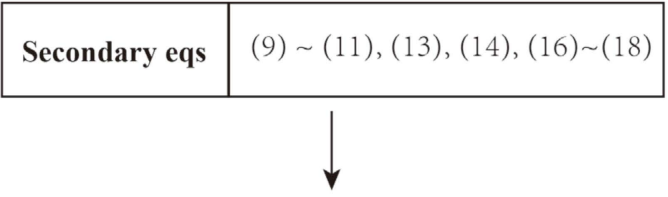

Variables including basic unknows solved<smiles>CC1([V])CCCCC1</smiles>

Step 2. Determine suspension density and circulation rate

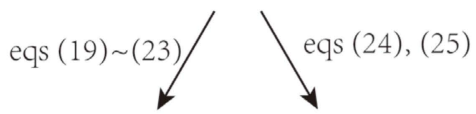

Solids suspension density Solids circulation rate $\rho_{i}$ profile

$$
G_{s p, i} \text { and } G_{s p}
$$

Figure 6. Solution procedure of theoretical calculation. 
The calculated value of pressure drops across the furnace, cyclones, and the connection are provided in Appendix B. The experimental data of pressure drops across the furnace and cyclones are also given there.

\section{Results and Discussion}

\subsection{Effect of Overall Resistance Coefficient on Suspension Density Distribution and $G_{s p}$}

Figure 7 shows solids suspension density distribution along with the furnace height with different overall resistance coefficient $\xi_{a v}$, from connection modes including A-type, B-type, and C-type. The theoretical results match well with the experimental data.

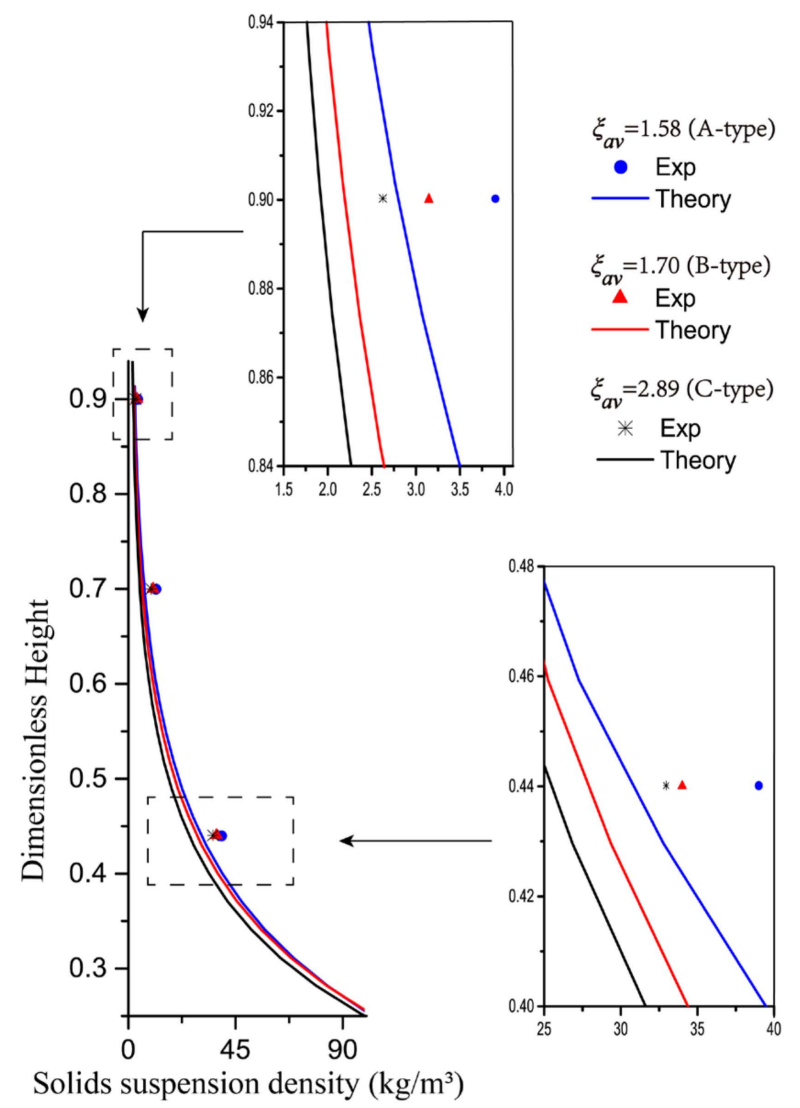

Figure 7. Axial gas-solid suspension density profile at different connection modes.

As mentioned in Section 3.2, the A-type connection mode has the smallest value of overall connection resistance coefficient $\xi_{a v}$. Figure 7 shows the largest suspension density in the furnace above the dense section compared to the other two connections. Besides, the smoothest slope of the suspension density curve along the height of the A-type mode can also be discovered. In contrast, there are fewer solids suspended in the furnace of the $\mathrm{B}$ and C-type connection modes, and their suspension density curves along bed height are steeper, reflecting more uneven axial suspension density distribution. This indicates the hydraulic resistance of the connection section affects the solids suspension density distribution in the furnace. Higher pressure resistance of the connection may result in a hindrance curtain at the exit of the furnace so as to prevent the gas-solid up-flowing from the furnace bottom to the top. As a result, the solids suspension density is distributed more non-uniformly in the furnace as $\xi_{a v}$ increases.

Figure 8 gives the results of the solids suspension density at specific heights and the average solids circulation rate among standpipes $\left(G_{s p}\right)$ with respect to the overall resistance coefficient $\xi_{a v}$. As illustrated in the figure, the solids suspension density in dense phase $\left(\rho_{a}\right)$ of C-type mode is around $30 \mathrm{~kg} / \mathrm{m}^{3}$ larger than that of A-type mode, while the concentration in furnace exit $\left(\rho_{e}\right)$ is $1.8 \mathrm{~kg} / \mathrm{m}^{3}$ less. In terms of average solids 
circulation rate among four standpipes $\left(G_{s p}\right)$, the A-type mode has the largest $G_{s p}$ value of near $100 \mathrm{~kg} / \mathrm{m}^{2} \mathrm{~s}$ which is around $20 \mathrm{~kg} / \mathrm{m}^{2} \mathrm{~s}$ larger than that of C-type mode.

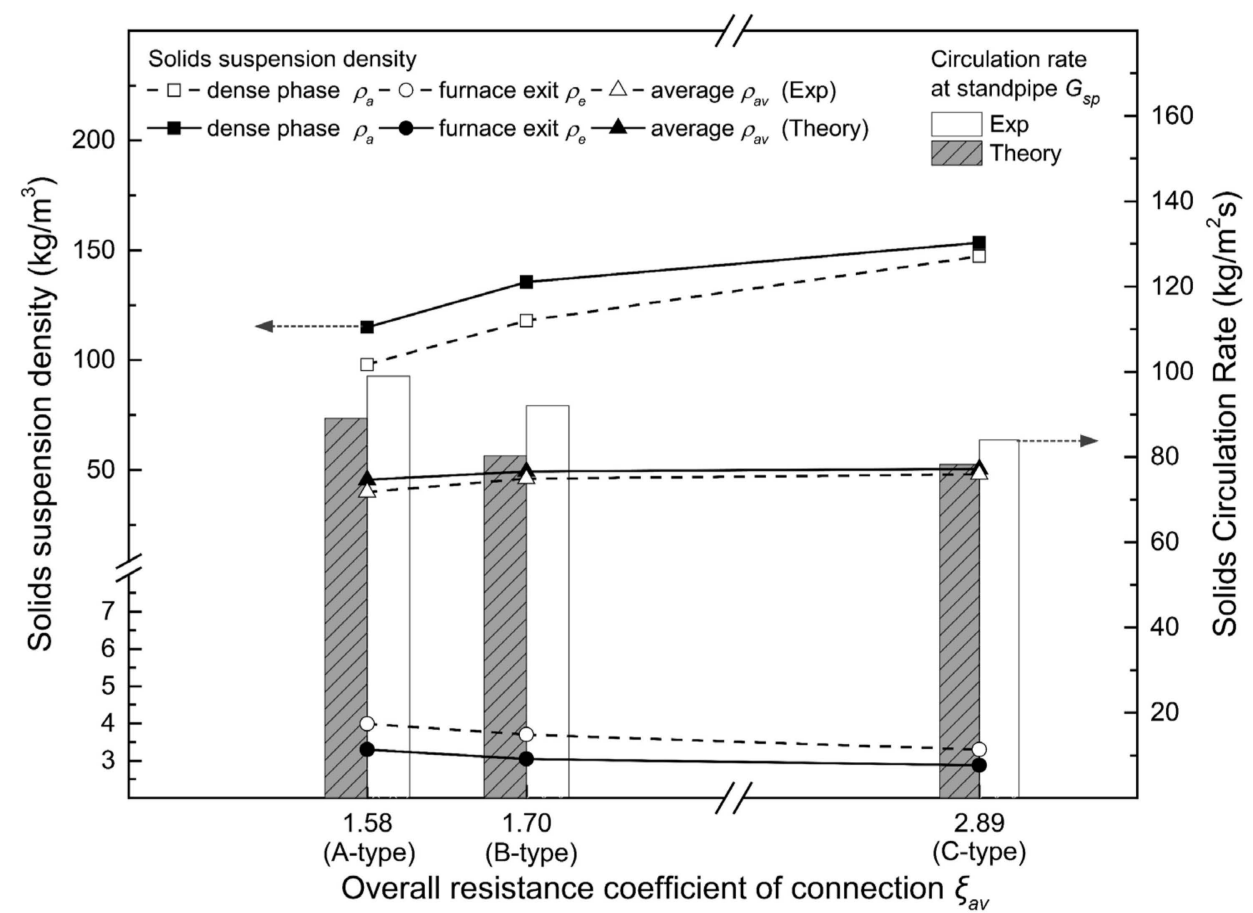

Figure 8. Solids suspension density and $G_{s p}$ in different connection modes.

Sum up with both Figures 7 and $8, \rho_{a}$ has the same trend as resistance coefficient $\xi_{a v}$ variation, while $\rho_{e}$ and $G_{s p}$ changes with $\xi_{a v}$ reversely. Meanwhile, the average solids suspension densities $\left(\rho_{a v}\right)$ do not change much for different $\xi_{a v}$.

From those results, it can be deduced that there are more solids transferred from the bottom to the upper furnace when the solids circulation rate increases and the solids circulation is intensified by smaller resistance of a connection. The high circulation rate exerts an effect on larger solids suspension density in the upper dilute zone. Therefore, small $\xi_{a v}$ in a connection mode would cause less hindrance for solids circulation and lifting, resulting in better uniformity of axial gas-solid distribution profile.

\subsection{Effect of Connection Branch Resistance Distribution on Suspension Density and $G_{s p, i}$}

To study the effect of the resistance distribution among connection branches on solids suspension density and the solids circulating rates $\left(G_{s p, i}\right)$ allocation further, more works were done on C-type connection mode.

The structure of the C-type connection was given in both Figures 4 and 9, there are four exit branch ducts extended from four cyclone outlets. Those ducts compile at different positions successively, forming four connection branches (No. 1-4) for gas flowing from each cyclone outlet to the backpass. As depicted from Figure 9, the resistance coefficients of the connection branches $\left(\xi_{b, i}\right)$ decrease from branch 1 to 4 as $3.3-2.0$, and the value of $\xi_{b, i}$ is smaller if the corresponding branch is closer to backpass. 


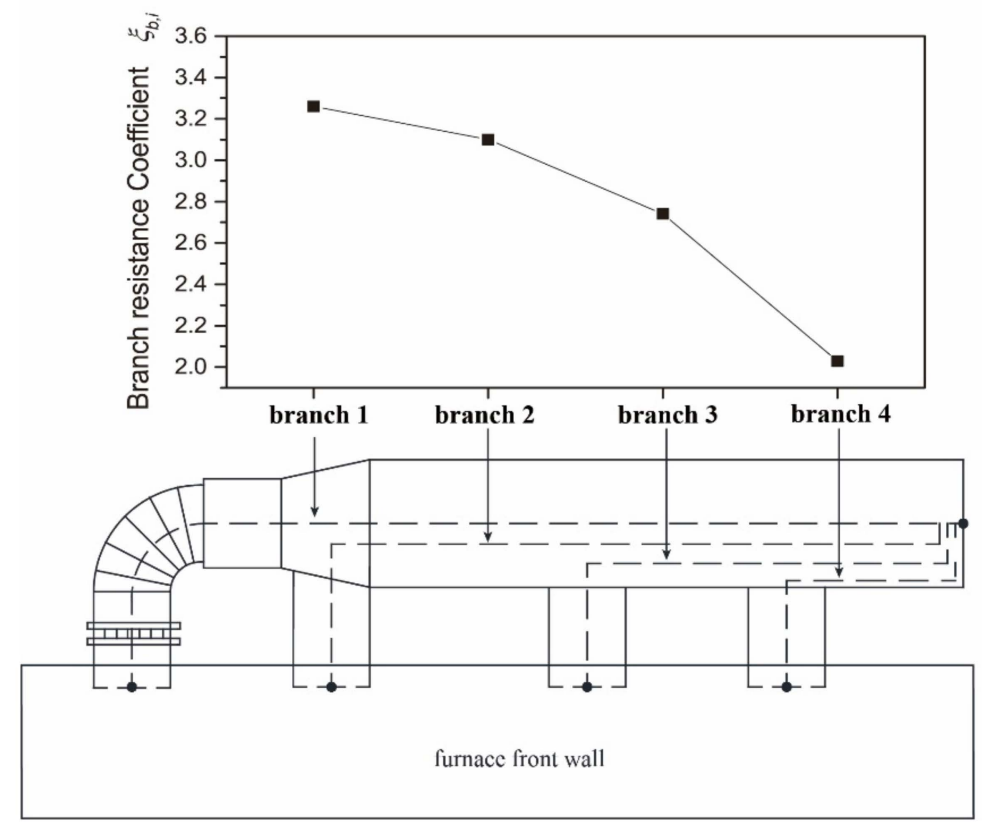

Figure 9. Branch resistance coefficient $\xi_{b, i}$ of C-type connection mode.

Figure 10 gives the solids suspension density distribution on the view of the furnace front wall obtained from the experiments and theoretical calculation. The experimental contour presents the solids suspension density in the furnace from three rows of measuring points (shown in Figure 1b). And the theoretical contour diagram shows the solids suspension density with dimensionless length from 0.2 to 0.8 which corresponding to the theoretical gas-flowing branch 1 to 4 in the furnace, as shown in Figure 5. It can be seen that solids suspension density in the dilute section increases from left to right, with around $3 \mathrm{~kg} / \mathrm{m}^{3}$ variance between branches 1 and 4 . And lateral density distribution in the furnace below the transition section $(H / h=0.3-0.5)$ remains relatively uniform for both experimental and theoretical contours.
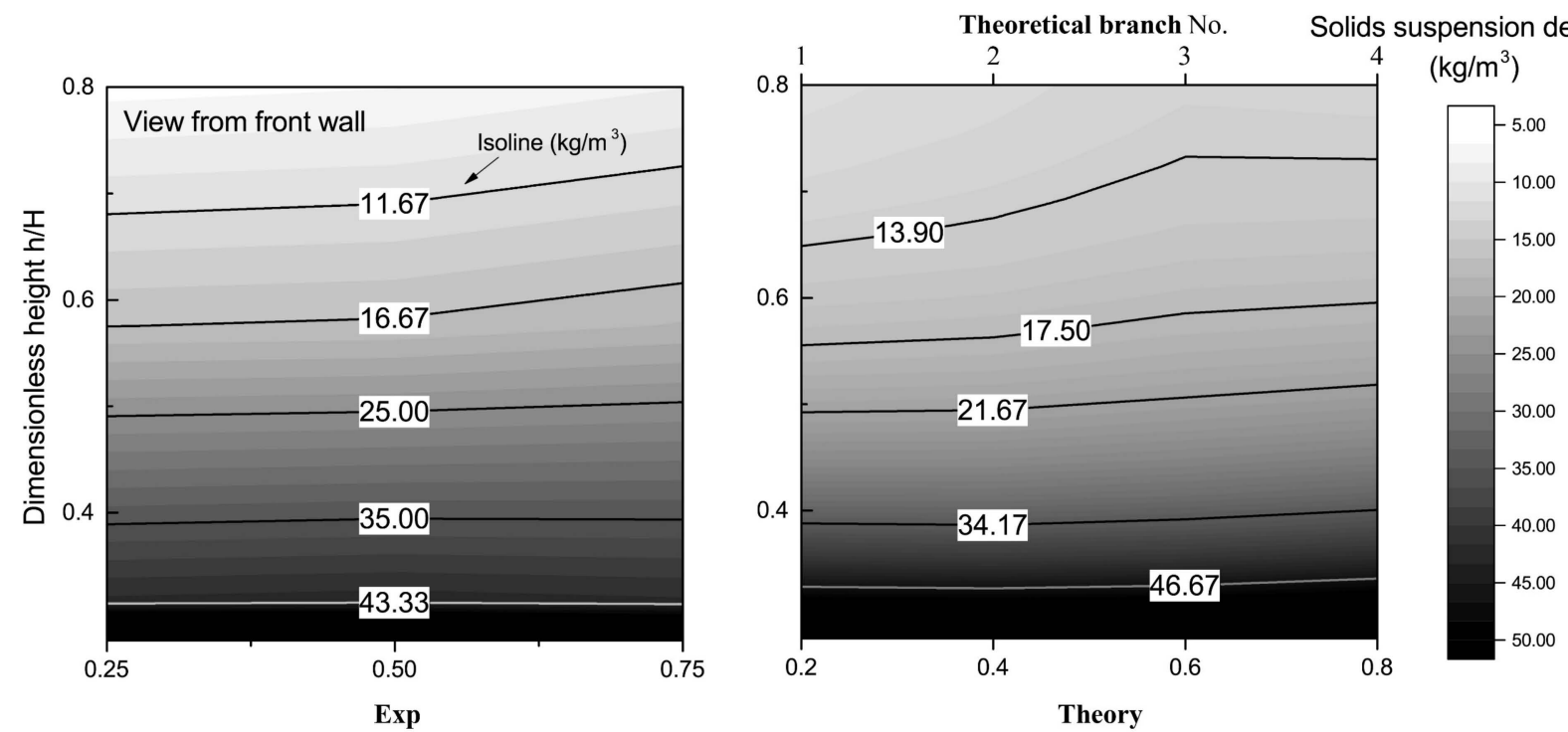

Dimensionless length position $x / L$

Figure 10. The contour of furnace suspension density of C-type mode. 
Figure 11 shows the relationship of standpipe circulation $G_{s p, i}$ distribution among each standpipe, corresponding to each connection branch. Both experimental and theoretical results presented higher $G_{s p, i}$ at lower resistance $\xi_{b, i}$ of a connection branch. To be specific, the circulation rate in branch 4 is the largest and $45 \mathrm{~kg} / \mathrm{m}^{2} \mathrm{~s}$ greater than that in branch 1 . The relationship between $G_{s p, i,}$ and $\xi_{b, i}$ have a similar trend as solids suspension density in the dilute section in Figure 10.

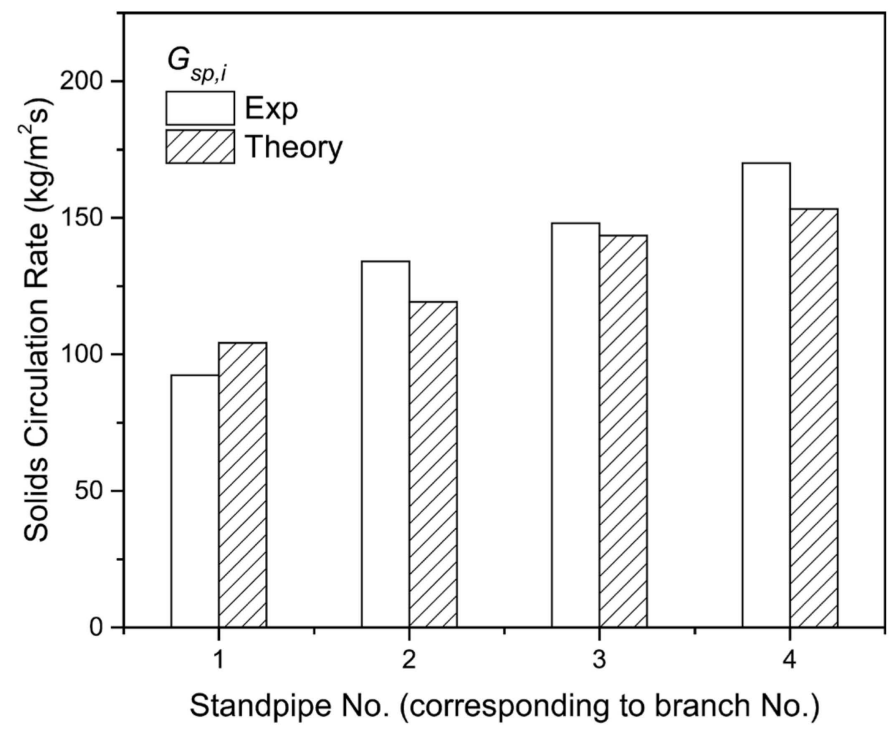

Figure 11. Solids circulation rate of four standpipes of C-type mode (corresponding to four connection branches).

Combined with Figures 10 and 11, it can be summarized that higher $\xi_{b, i}$ of a connection branch may also hinder solids circulation in the corresponding solids recycle loop and consequently reduce furnace solids suspension density in this gas-flowing branch. And the axial solids suspension density distributed more non-uniform with higher $\xi_{b, i}$ of a connection branch.

\subsection{Effect of Superficial Velocity on Suspension Density and Circulation Rate}

The superficial velocity has a strong impact on furnace solids suspension density distribution, solids circulation rates, and their uniformity. In this section, four different velocity conditions are tested with $F n$ number of 85.2, 91.4, 96.3, 102.5, and corresponding velocities of $0.68,0.73,0.78,0.83(\mathrm{~m} / \mathrm{s})$. The lower limit of the velocity conditions is considering terminal velocity's value of $0.66 \mathrm{~m} / \mathrm{s}$ that superficial velocity should be larger than that. And the upper limit of $0.83 \mathrm{~m} / \mathrm{s}$ corresponds to the superficial velocity of the original boiler of $5.26 \mathrm{~m} / \mathrm{s}$ at 100\% Boiler Maximum Continuous Rating (BMCR).

Figure 12 presents the effect of superficial velocity on a solids suspension density on the above furnace dense zone in three connection modes. A smoother curve and larger values of the solids suspension density are achieved when $\xi_{a v}$ of a connection mode decreases at all velocities. For different velocity conditions, the axial variance of the solids suspension becomes larger with growing superficial velocity, especially at the lower section. 

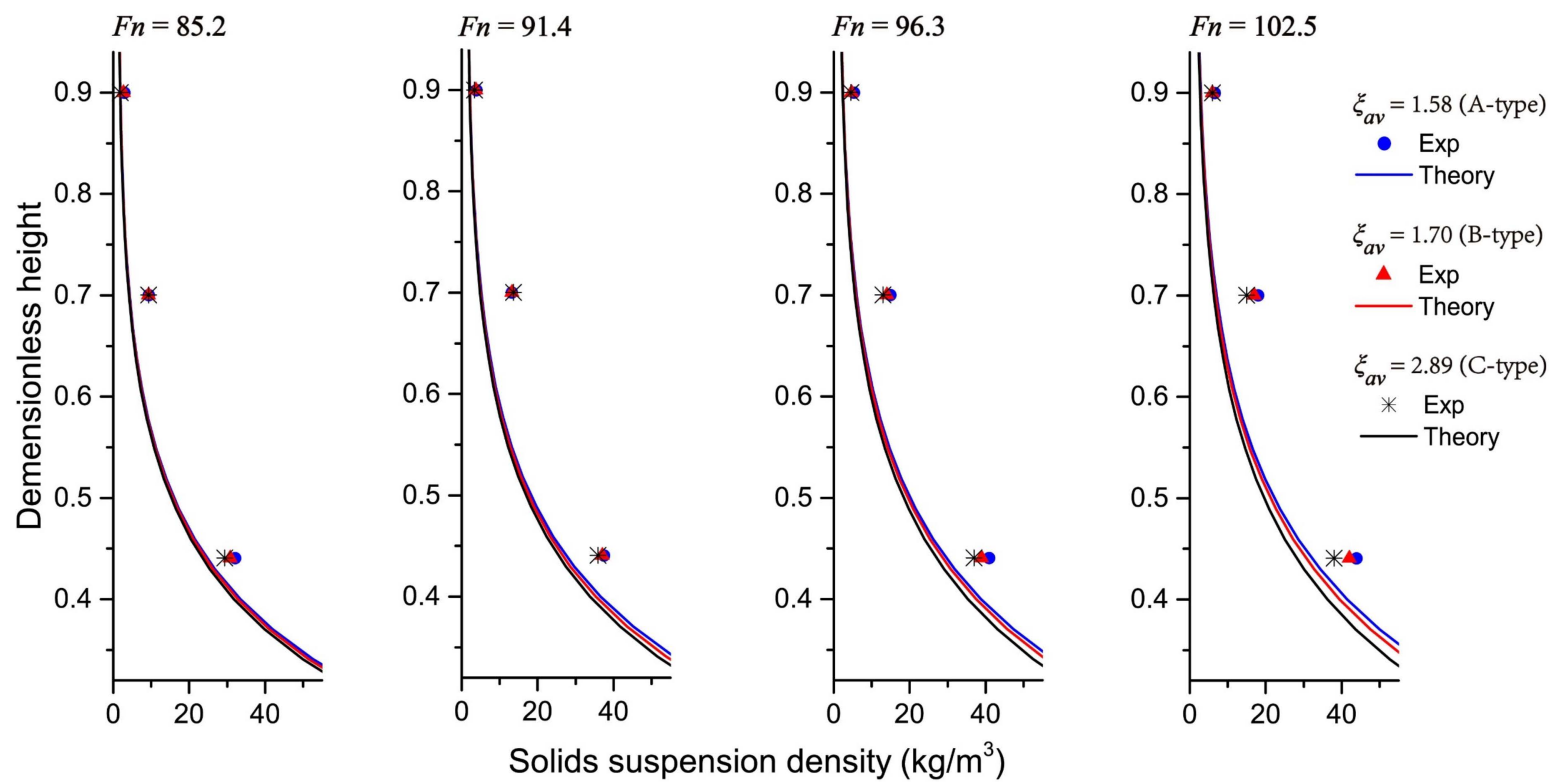

Figure 12. Effect of superficial velocity on suspension density with different $\xi_{a v}$.

Figure 13 gives the effect of superficial velocity on a solids suspension density from Ctype connection mode. The No. 4 connection branch, with the smallest resistance coefficient $\xi_{b, i}$, has the largest solids suspension density in the furnace. The suspension density distribution curves show a similar trend with the results from different connection modes in Figure 12. That is, the effect of connection resistance on solids suspension distribution variation can be intensified by increasing superficial velocity. This intensification is most stimulated in the furnace lower section.
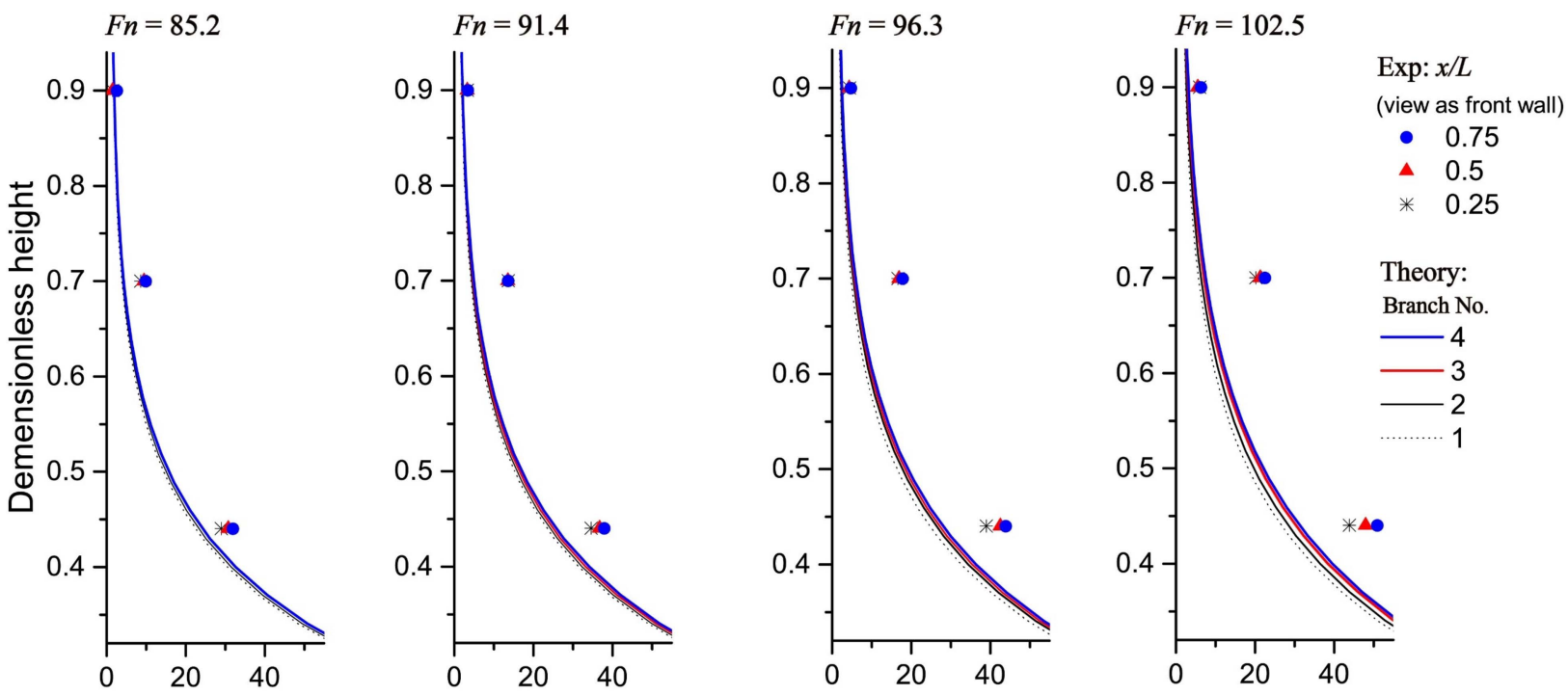

Solids suspension density $\left(\mathrm{kg} / \mathrm{m}^{3}\right)$

Figure 13. Effect of superficial velocity on solids suspension density (C-type mode).

Figure 14 presents the effect of superficial velocity on solids circulation rates with different $\xi_{a v}$. Both theoretical and experimental results show average circulation rate $G_{s p}$ increases with the superficial velocity in all cases. A circulating system with smaller overall connection resistance $\xi_{a v}$ has a larger circulation rate. It can also be depicted from the figure that, for all connection modes, once increasing the superficial velocity, the value of $G_{s p}$ and range of $G_{s p, i}$ among standpipes are enlarged. This indicates higher non-uniformity of $G_{s p, i}$ 
with increasing superficial velocity. And the velocity effect is most stimulated in C-type mode, probably because of its most uneven $\xi_{b, i}$ distribution.

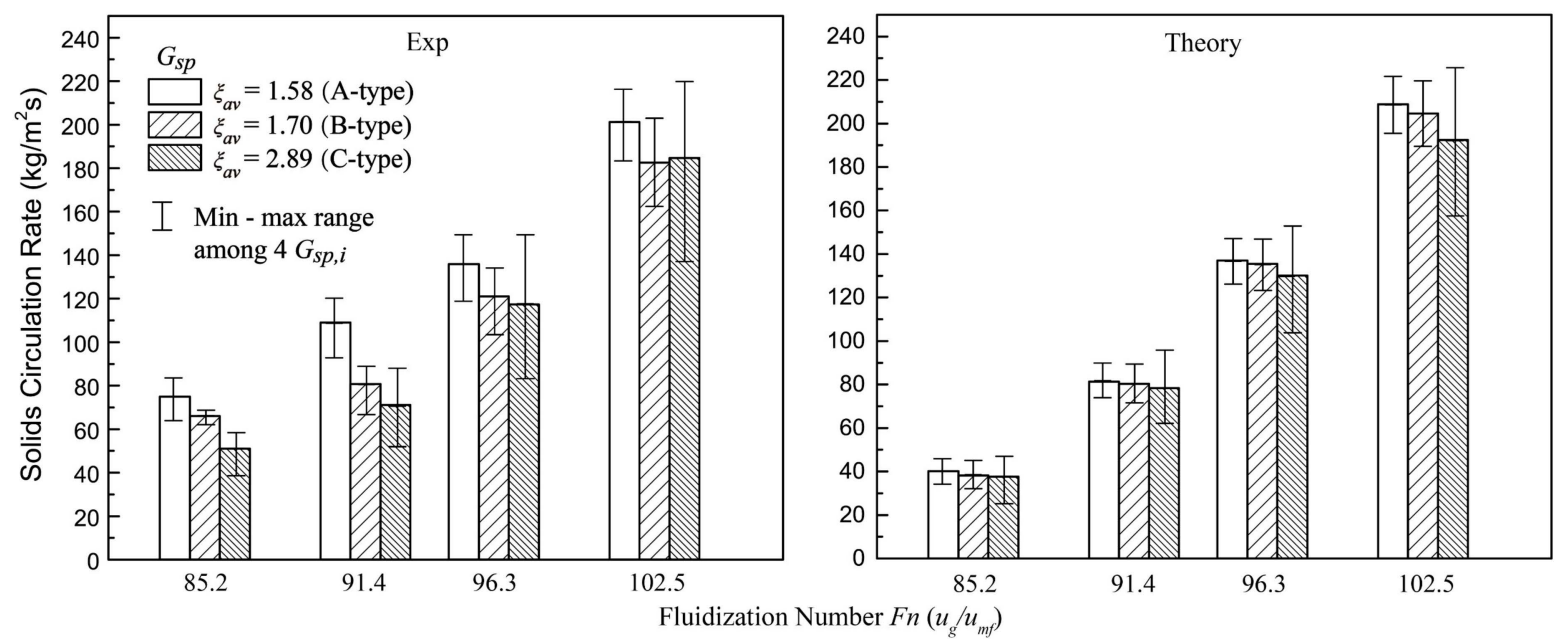

Figure 14. Effect of superficial velocity on solids circulation rate $G_{s p}$ with different $\xi_{a v}$.

The effect of superficial velocity on $G_{s p, i}$ in each solids recycle loop from the C-type connection mode is shown in Figure 15. Increasing superficial velocity intensifies solids circulation rate at all recycle loops. However, this enhancement effect varies with different recycle loops (standpipe No.). The recycle loop with larger corresponding $\xi_{b, i}$ (e.g., No. " 1 ") has slighter changes in circulation rate with superficial velocity. On contrary, the recycle loop No. " 4 " has the smallest corresponding $\xi_{b, i}$, and its circulation rate increases most enormously with superficial velocity. The different responding effects for superficial velocity among each standpipe can also explain the phenomenon in Figure 14 that, the non-uniformity among $G_{s p, i}$ is enlarged with growing superficial velocity.
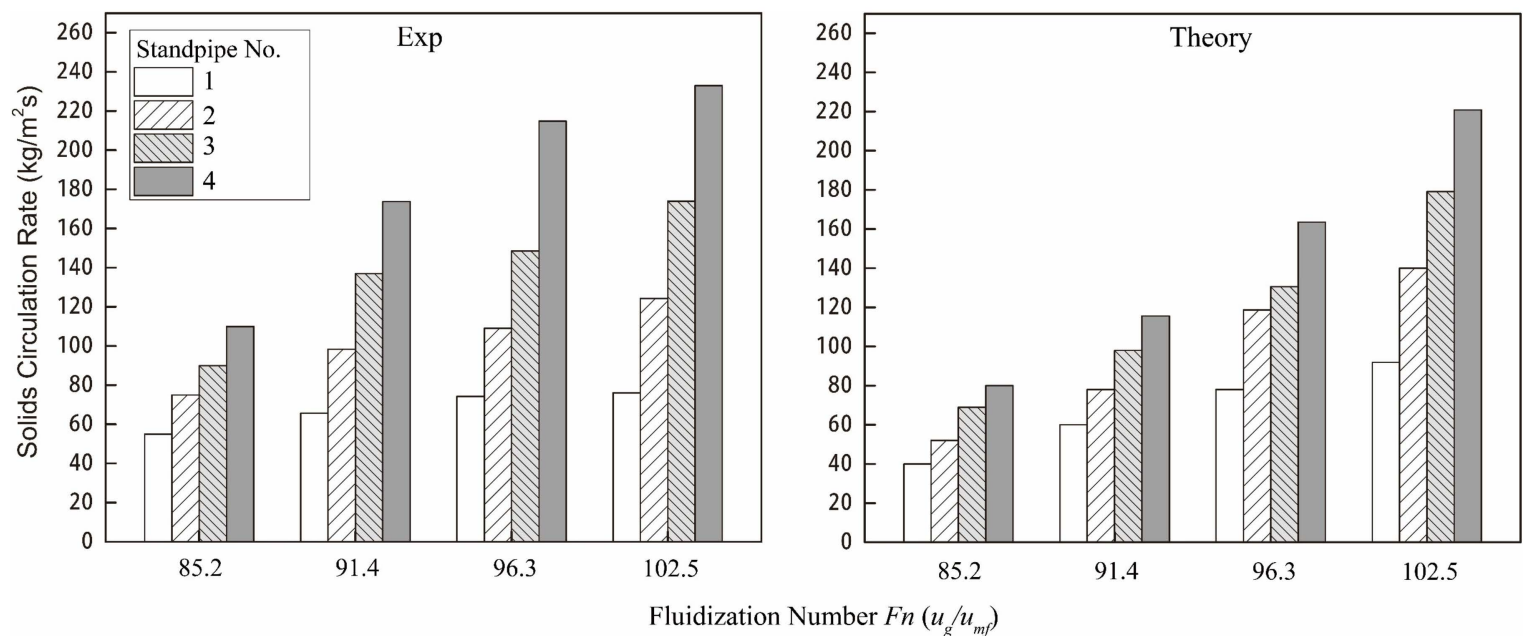

Figure 15. Effect of superficial velocity on $G_{s p, i}$ in each standpipe (C-type mode).

Combined with Figures 12-15, it is apparent that the non-uniformity of furnace solids suspension distribution and solids circulation rate caused by connection resistance is enhanced by superficial velocity. This can be further analyzed that, although $\xi_{a v}$ of connection or $\xi_{b, i}$ among branches is constant, the connection pressure drop $\left(\Delta P_{E F, i}\right.$ in Equation (8) and variation among $\Delta P_{E F, i}$ in different branches are increased by growing velocity. As a result, the furnace gas-solid distribution profile and circulation rates allocation become more uneven with increasing superficial velocity. 


\section{Conclusions}

\subsection{The Conclusions for the Investigation}

The effect of connection resistance between cyclones and backpass on furnace solids suspension density distribution and solids circulation rates in a multi-cyclone CFB was investigated. The main conclusions are:

(1) The solids suspension density in the furnace and solids circulation rate distributions are influenced by connection resistance. With smaller overall resistance coefficient $\xi_{a v}$ of a connection, the axial solids suspension density in the furnace distributes more uniform and solids circulation rate becomes larger;

(2) For branch resistances $\xi_{b, i}(i=1-4)$ in a connection, smaller $\xi_{b, i}$ leads to higher solids circulation rate in solids recycle loop. Regarding C-type connection mode, the $\xi_{b, i}$ is decreasing from connection branch 1 4, resulting in solids suspension density and circulation rates increasing from corresponding recycle loop $1-4$. Smaller $\xi_{b, i}$ of a connection branch also leads to more evenly axial solids suspension density distribution of corresponding recycle loop;

(3) The effect of connection resistance is enhanced by growing superficial velocity. The variance of lateral solids suspension distribution and solids circulation rates allocation becomes larger with higher superficial velocity. For a connection, non-uniformity of branch resistance $\xi_{b, i}$ affects the uneven distribution of solids suspension density and $G_{s p, i}$ allocation among recycling loops, this effect is strongly intensified by growing velocity.

\subsection{Suggestions for the Connection Design of Large Scale CFB Boiler}

The connection resistance and its distribution between cyclones and backpass should be paid more attention when designing an industry CFB boiler. Some suggestions are given as follows,

(1) It is beneficial to design a simple connection structure with a short distance from cyclones to the backpass. A a small value of overall connection resistance coefficient $\xi_{\text {av }}$ should be chosen, for it leads to less resistance for gas-solid circulation and is helpful for operating flexibly.

(2) For each connection branch in a connection mode, the structure and distance from each cyclone to backpass should be close to each other, ensuring uniformity of branch resistance coefficient $\xi_{b, i}$ distribution. It is helpful to diminish uneven solids suspension density distribution and solids circulation rates allocation.

Author Contributions: Conceptualization, G.L. and L.C.; methodology, G.L., L.C., L.L. and W.Z.; validation, L.C., J.W. and X.J.; investigation, G.L., L.C., J.W. and X.J.; resources, W.Z., J.W. and X.J.; writing—original draft preparation, G.L.; writing—review and editing, L.C. and L.L.; funding acquisition, L.C. All authors have read and agreed to the published version of the manuscript.

Funding: This work was supported by the National Key Research \& Development Program of China (No. 2020YFB0606201). The program's funder is Ministry of Science and Technology of the People's Republic of China.

Institutional Review Board Statement: Not applicable.

Informed Consent Statement: Not applicable.

Data Availability Statement: Not applicable.

Conflicts of Interest: The authors declare no conflict of interest. 


\section{Nomenclature}

\section{Symbol Explanation}

$A_{c} \quad$ Cross-section area of cyclone entrance

$A_{\text {dis }} \quad$ Cross-section area of non-machanical valve

$A_{f} \quad$ Cross-section area of furnace

$A_{s p} \quad$ Cross-section area of standpipe

Ar Archimedes number

$D \quad$ Width of furnace cross-section $\mathrm{m}$

$d_{c} \quad$ Diameter of cyclone $\mathrm{m}$

$d_{s} \quad$ Diameter of standpipe

$d_{p} \quad$ Particle diameter

Fn Fluidization number

g Gravitational constant

$G_{S} \quad$ Solids circulation rate

$G_{s f} \quad$ Solids circulation rate at furnace

$G_{s p, i} \quad$ Solids circulation rate at standpipe " $i$ "

$G_{s p} \quad$ Average solids circulation rate among standpipes

$h_{0} \quad$ Height of dense phase

$H \quad$ Height of furnace

$H_{0} \quad$ Bed inventory height

$i \quad$ No. of theoretical gas branch/solids recycle loop

$L \quad$ Length of furnace cross-section

$M \quad$ Total solids inventory in CFB system $\quad \mathrm{kg}$

$\begin{array}{lll}M_{s p} & \text { The mass of solids in standpipe } & \mathrm{kg}\end{array}$

$\begin{array}{lll}M_{f} & \text { The mass of solids in furnace } & \mathrm{kg}\end{array}$

$\begin{array}{lll}M_{c y c} & \text { The mass of solids in cyclones } & \mathrm{kg}\end{array}$

$\triangle P \quad$ Pressure drop $\quad \mathrm{Pa}$

$\triangle \mathrm{P}_{A B, i} \quad$ Pressure drop across furnace of a solids recycle loop $\quad \mathrm{Pa}$

$\triangle P_{A B} \quad$ Pressure drop across furnace, $\frac{1}{4} \sum \Delta P_{A B, i}(i=1-4) \quad \mathrm{Pa}$

$\triangle P_{B E, i} \quad$ Pressure drop across cyclone of a solids recycle loop $\quad \mathrm{Pa}$

$\triangle P_{B E} \quad$ Pressure drop across cyclones, $\frac{1}{4} \sum \Delta P_{B E, i}(i=1-4) \quad$ Pa

$\triangle P_{E F, i} \quad$ Pressure drop across a connection branch $\quad \mathrm{Pa}$

$\triangle P_{E F} \quad$ Pressure drop across a connection, $\frac{1}{4} \sum \Delta P_{E F, i}(i=1-4) \quad \mathrm{Pa}$

$\triangle P_{C D, i} \quad$ Pressure drop across standpipe of a recycle loop $\quad \mathrm{Pa}$

$\Delta P_{D A, i} \quad$ Pressure drop across loop-seal of a recycle loop $\quad \mathrm{Pa}$

$R e_{p} \quad$ Particle Reynolds number -

$R_{t} \quad$ Terminal particle Reynolds number -

$u_{g} \quad$ Superficial velocity in furnace $\mathrm{m} / \mathrm{s}$

$u_{g, i} \quad$ Superficial velocity in furnace of a gas flowing branch $i \quad \mathrm{~m} / \mathrm{s}$

$u_{m f} \quad$ Minimum fluidized velocity $\mathrm{m} / \mathrm{s}$

$u_{t} \quad$ Terminal velocity $\mathrm{m} / \mathrm{s}$

$u_{v s} \quad$ Air velocity in supply chamber $\mathrm{m} / \mathrm{s}$

$u_{v r} \quad$ Air velocity in recycle chamber $\mathrm{m} / \mathrm{s}$

$\xi_{\text {av }} \quad$ Overall resistance coefficient of a connection mode

$\xi_{b, i} \quad$ Resistance coefficient of connection branch " $i$ "

$\xi_{f r, i} \quad$ Friction resistance coefficient of connection branch " $i$ "

$\xi_{l, i} \quad$ local resistance coefficient of connection branch " $i$ "

$\rho_{i} \quad$ Solids suspension density of a gas flowing branch

$\rho_{a, i} \quad$ Solids suspension density in dense phase of a gas flowing branch

$\bar{\rho}_{a} \quad$ Average solids suspension density in dense phase

$\rho_{a v, i} \quad$ Average solids suspension density above furnace bottom of a branch

$\rho_{a v} \quad$ Average solids suspension density in furnace

$\rho_{b} \quad$ Particle bulk density 


$\begin{array}{lll}\rho_{d, i} & \text { Saturated carrying capacity of a gas at certain velocity } & \mathrm{kg} / \mathrm{m}^{3} \\ \rho_{e, i} & \text { Solids suspension density at the furnace exit of a branch } & \mathrm{kg} / \mathrm{m}^{3} \\ \rho_{e} & \text { Average solids suspension density at the furnace exit } & \mathrm{kg} / \mathrm{m}^{3} \\ \rho_{f} & \text { Air density } & \mathrm{kg} / \mathrm{m}^{3} \\ \rho_{s} & \text { Particle density } & \mathrm{kg} / \mathrm{m}^{3} \\ \rho_{s u s} & \text { Solids suspension density } & \mathrm{kg} / \mathrm{m}^{3} \\ v & \text { Kinetic Viscosity } & \mathrm{m}^{2} / \mathrm{s} \\ \varepsilon_{a, i} & \text { Voidage at furnace bottom of a branch } & - \\ \bar{\varepsilon}_{a} & \text { Average voidage at furnace bottom } & \\ \varepsilon_{d, i} & \text { Saturated solids carrying capacity voidage of a furnace branch } & - \\ \varepsilon_{m f} & \text { Minimum fluidized voidage } & - \\ \Phi & \text { Sphericity of particle } & -\end{array}$

\section{Appendix A. The Calculation of Terminal Velocity}

The calculation method for terminal velocity $u_{t}$ is described in this section. Firstly it is calculated through terminal Reynold number $R e_{t}$,

$$
R e_{t}=\frac{u_{t} d_{p}}{v}
$$

And the terminal particle Reynold number is related to Archimedes number $A r$. The calculation differs from various flowing conditions [28],

$$
\begin{aligned}
& R e_{t}=\frac{A r}{18} \quad \text { Stokes }^{\prime} \text { Law } \quad\left(0<R e_{t}<0.4\right) \\
& R e_{t}=\left(\frac{A r}{7.5}\right)^{0.666} \quad \text { Intermediate Law } \quad\left(0.4<R e_{t}<500\right) \\
& R e_{t}=\left(\frac{A r}{0.33}\right)^{0.5} \quad \text { Newtons' Law } \quad\left(R e_{t}>500\right)
\end{aligned}
$$

Here the Archimedes number can be expressed as,

$$
A r=\frac{d_{p}^{3} \mathrm{~g} \rho_{f}\left(\rho_{s}-\rho_{f}\right)}{\mu^{2}}
$$

where $\mu$ is the dynamic viscosity of fluid and $\mu=v \rho_{f}$.

In this study, the value of $d_{p}, v, \rho_{s}$, etc. can be found in Table 1 . The calculated results of $u_{t}$ and $R e_{t}$ are equaled to $0.66 \mathrm{~m} / \mathrm{s}$ and 3.2, respectively, corresponding to the "Intermediate Law".

\section{Appendix B. The Pressure Drop Across Furnace, Cyclones and The Connections}

The pressure drops across furnace $\left(\Delta P_{A B}\right)$ and cyclones $\left(\Delta P_{B E}\right)$ were recorded during the experiments with A, B, and C-type connection modes. The data is listed in Table A1. Meanwhile, Table A2 gives the calculated pressure drops of furnace, cyclones, and connections $\left(\triangle P_{E F}\right)$.

It needs to notice that for Table $A 1, \Delta P_{A B}$ is calculated by averaging the pressure drops of three measuring rows, while for Table $\mathrm{A} 2$ it is the average value of four theoretical solids recycle loops $\Delta P_{A B}=\frac{1}{4} \sum \Delta P_{A B, i}(i=1-4)$. The same methods are applied in $\Delta P_{B E}$ and $\triangle P_{E F}$. 
Table A1. Pressure drop across furnace and cyclones (Exp. unit of Pa).

\begin{tabular}{ccc}
\hline Type of Connection Modes & $\boldsymbol{\Delta} \boldsymbol{P}_{\boldsymbol{A B}}$ & $\boldsymbol{\Delta} \boldsymbol{P}_{\boldsymbol{B E}}$ \\
\hline A-type & 595.9 & 63.2 \\
B-type & 645.2 & 66.4 \\
C-type & 661.6 & 65.2 \\
\hline
\end{tabular}

Table A2. Pressure drop across furnace, cyclones, and connection (Theory, unit of Pa).

\begin{tabular}{cccc}
\hline Type of Connection Modes & $\boldsymbol{\Delta} \boldsymbol{P}_{\boldsymbol{A B}}$ & $\boldsymbol{\Delta} \boldsymbol{P}_{\boldsymbol{B E}}$ & $\boldsymbol{\Delta} \boldsymbol{P}_{\boldsymbol{E F}}$ \\
\hline A-type & 604.6 & 57.1 & 32.4 \\
B-type & 653.2 & 57.5 & 38.2 \\
C-type & 667.1 & 58.2 & 49.5 \\
\hline
\end{tabular}

\section{References}

1. Zhou, X.L.; Cheng, L.M.; Zhang, J.; Wang, Q.H.; Luo, Z.Y.; Cen, K.F. Experimental Study on Solids Suspension Density and Solids Circulating Rate in a CFB with Six Circulating Loops. Proc. CSEE 2012, 32, 31-36.

2. Wang, F.J.; Song, G.L.; Wang, X.F.; Liu, Z.C.; Sun, Y.K.; Lu, Q.G. Cold Experimental Study on a CFB with Four Cyclone Separators on the Same Side. Power Syst. Eng. 2014, 3, 17-19.

3. Lee, J.M.; Kim, J.S.; Kim, J.J. Characteristics of Solid Hold Up and Circulation Rate in the CFB Reactor with 3-Loops. Korean J. Chem. Eng. 2001, 18, 1000-1004. [CrossRef]

4. Yang, S.; Yang, H.R.; Liu, Q.; Zhang, H.; Wu, Y.X.; Yue, G.X.; Wang, Y.Z. Research on Flow Non-Uniformity in Main Circulation Loop of a CFB Boiler with Multiple Cyclones. In Proceedings of the 20th International Conference on Fluidized Bed Combustion, Xi'an, China, 18-21 May 2009; Springer: Berlin/Heidelberg, Germany, 2009; Volume 139, pp. 341-344.

5. Zheng, W.J.; Zhang, M.; Zhang, Y.; Lyu, J.F.; Yang, H.R. The effect of the secondary air injection on the gas-solid flow characteristics in the circulating fluidized bed. Chem. Eng. Res. Des. 2019, 141, 220-228. [CrossRef]

6. Karlsson, T.; Liu, X.; Pallarès, D.; Johnsson, F. Solids circulation in circulating fluidized beds with low riser aspect ratio and varying total solids inventory. Powder Technol. 2017, 316, 670-676. [CrossRef]

7. Mo, X.; Cai, R.X.; Huang, X.D.; Zhang, M.; Yang, H.R. The effects of wall friction and solid acceleration on the mal-distribution of gas-solid flow in double identical parallel cyclones. Powder Technol. 2015, 286, 471-477. [CrossRef]

8. Harris, A.T.; Davidson, J.F.; Thorpe, R.B. Influence of exit geometry in circulating fluidized-bed risers. AIChE J. 2003, 49, 52-64. [CrossRef]

9. Wang, S.; Luo, K.; Hu, C.S.; Fan, J.R. CFD-DEM study of the effect of cyclone arrangements on the gas-solid flow dynamics in the full-loop circulating fluidized bed. Chem. Eng. Sci. 2017, 172, 199-215. [CrossRef]

10. Knowlton, T.M. Standpipes and return systems. In Circulating Fluidized Beds; Springer: Dordrecht, The Netherlands, 1997; pp $214-260$

11. Sun, X.B.; Li, G.H.; Jiang, M.H. Study on Several Forward Tasks in the Technical Sector of CFB Boilers. Therm. Power Gener. 2005, $34,1-5$.

12. Song, G.L.; Yang, Z.; Zhou, T.; Lyu, Q.G. Operating technical characteristics on asymmetrical arrangement of six cyclones in a 600 MW supercritical CFB boiler. Appl. Therm. Eng. 2018, 143, 236-247. [CrossRef]

13. Mo, X.; Cai, R.X.; Lyu, J.F. Analysis of Non-uniform Distribution of Gas-Solid Flow in the 600 MW(e) CFB Boiler Based on the Non-uniform Distribution of Returning Ash Temperature. Proc. CSEE 2016, 36, 153-158.

14. Glicksman, L.R. Scaling relationships for fluidized beds. Chem. Eng. Sci. 1984, 39, 1373-1379. [CrossRef]

15. Glicksman, L.R. Scaling relationships for fluidized beds. Chem. Eng. Sci. 1988, 43, 1419-1421. [CrossRef]

16. Idelcik, I.E.; Ginevskiy, A.S.; Kolesnikov, A.V. Handbook of Hydraulic Resistance; Hemisphere Publishing Corp.: Washington, DC, USA, 1986.

17. Zheng, Y.; Lu, X.F.; Yang, W.Q.; Fan, L.Y.; Wang, Q.H.; Yan, J. Simulation of Particle Concentration Distribution in a Large-scale Circulating Fluidized Bed Boiler at Different Material-returning Deviations. Proc. CSEE 2020, 40, 848-858.

18. Bi, H.; Zhu, J.X. Static instability analysis of circulating fluidized beds and concept of high-density risers. AIChE J. 1993, 39, 1272-1280. [CrossRef]

19. Shepherd, C.B.; Lapple, C.E. Flow Pattern and Pressure Drop. Ind. Eng. Chem. 1939, 31, 972-984. [CrossRef]

20. Chen, H.Z.; Yang, D.W.; Li, H.Z.; Tan, S.Y. Study on the overall pressure balance of a downflow circulating fluidized bed system. China Particuology 2006, 4, 153-159. [CrossRef]

21. Rhodes, M.J.; Geldart, D. A model for the circulating fluidized bed. Powder Technol. 1987, 53, 155-162. [CrossRef]

22. Bai, D.; Issangya, A.S.; Zhu, J.X.; Grace, J.R. Analysis of the Overall Pressure Balance around a High-Density Circulating Fluidized Bed. Ind. Eng. Chem. Res. 1997, 36, 3898-3903. [CrossRef] 
23. Kunii, D.; Levenspiel, O. Entrainment of solids from fluidized beds I. Hold-up of solids in the freeboard II. Operation of fast fluidized beds. Powder Technol. 1990, 61, 193-206. [CrossRef]

24. Basu, P. Circulating Fluidized Bed Boilers; Springer International Publishing: Cham, Switzerland, 2015; Volume 54, ISBN 978-3-31906172-6.

25. Yang, W.C. Criteria for choking in vertical pneumatic conveying lines. Powder Technol. 1983, 35, 143-150. [CrossRef]

26. Schlichthaerle, P.; Werther, J. Axial pressure profiles and solids concentration distributions in the CFB bottom zone. Chem. Eng. Sci. 1999, 54, 5485-5493. [CrossRef]

27. Stollhof, M.; Penthor, S.; Mayer, K.; Hofbauer, H. Estimation of the solid circulation rate in circulating fluidized bed systems. Powder Technol. 2018, 336, 1-11. [CrossRef]

28. Howard, J.R. Fluidized Bed Technology_Principles and Applications; CRC Press: Bristol, UK, 1989. 